\title{
STATE ADMINISTRATIVE MACHINERY FOR LIQUOR CONTROL
}

\author{
Grorge A. Shipman*
}

As long ago as Ig04, Ernst Freund wrote with respect to the regulation of the sale of alcoholic beverages, "There is hardly any other branch of law in which there has been so much shifting and reversing of policies." 1 This statement, intended as a summary of prior experience, proved to be prophetic of the years ahead. During Prohibition, regulatory policies assumed a superficial uniformity, but beneath the surface of constitutional restraint there developed the widest variety of local practices. These ranged from rigid suppression to easy toleration of an extra-legal liquor trade. In a sense local values could not be "repealed" by the adoption of Prohibition. In widespread areas an entirely new traffic in alcoholic beverages developed often dominated by professional criminals and accepted by otherwise law-abiding citizens as an unwelcome but necessary evil. Enforcement policies continued to fluctuate, more rapidly than in pre-Prohibition days, since there was no longer the stabilizing force of formalized toleration and official supervision. From many standpoints Repeal meant a return to legal rule and defined discretion.

\section{State Problems After Repeal}

In a legal sense Repeal meant the abandonment of rigid national control and a return to state regulation protected by the terms of the Twenty-first Amendment, which were reminiscent of the provisions of the Webb-Kenyon Act of r913. ${ }^{2}$ Within each state there were rather definite ideas of what future action should be like, colored in large part by what was understood to be the lessons of the past 15 years. It would not be feasible to attempt a complete presentation of the great variety of viewpoints held in the several localities. However, so far as they expressed a resolution to accomplish' a more effective public control, these attitudes were certainly important: 3

x. The legalization of the liquor business was intended to stamp out the illicit trade in all of its wide-reaching ramifications from "rum-row" off the sea coast to the distiller of "corn" in a lonely mountain hollow.

* B.A., r925, M.A., 1926, Wesleyan University; Ph.D., I93I, Cornell University. Associate Professor of Political Science, Duke University. Consultant in Public Law and Administration, State of West Virginia, since 1933. Research Associate, Princeton Local Government Survey, Princeton University 19351938. Consultant in Public Administration, Princeton Local Government Survey, since 1938.

${ }^{1}$ Freund, The Police Power (I904) I94, n. 2. ${ }^{2} 37$ Stat. 699.

${ }^{3}$ In this connection see Harrison and Laine, After Repeal (1936) $1-6$. 
2. The saloon-the corner drinking place-was not to return.

3. Since light beer and wines, defined generally as containing not more than 3.2 percent of alcohol by weight, were "non-intoxicating," their use was to be encouraged as a satisfying substitute for high-proof distilled spirits. ${ }^{4}$

4. Severe restrictions were to be placed upon operators in the liquor business to bar the return of a "whiskey trust," "tied houses" and other interlocking ownerships centralizing the profit motive but obscuring the responsibility for the conduct of retail business.

5. Dry areas were to be protected. Local districts desiring to remain "bone-dry" were to be guaranteed the privilege of local option.

The objectives of Repeal found a variety of expressions in state legislation. It would be hazardous to conclude that standard forms of control developed. From state to state different combinations of devices added up to quite different patterns of control. A few dominating characteristics stood out. In contrast to pre-Prohibition regulation, Repeal legislation emphasized a far greater degree of state control; broad discretion was granted to state administrative agencies to assure the ends of regulation; and for the first time proprietary action in the form of a state liquor monopoly was developed on a broad scale. All of these efforts are proving to be of the utmost significance, and they may provide the proving ground for regulatory methods that will find application elsewhere in the state control of economic activity. ${ }^{5}$

In retrospect it seemed that the major share of trouble caused by the sale of alcoholic liquors was occasioned by the public drinking place, an institution which was as much a local social center of dubious character as a dispensary of intoxicating beverages. That firm resolve that the saloon should not return takes concrete legislative form in the separation of "package" from "on-premise" sale." "Onpremise" sale is further limited in a number of states to bona fide restaurants and hotels. ${ }^{7}$ These restrictions express a purpose that alcoholic beverages may be sold as

\footnotetext{
"The separate treatment of " 3.2 beer" began with the enactment on Mar. 22, I933 of a law (48 STAr. r6), which imposed a special tax upon beer and liquor containing one-half percent or more but not more than 3.2 percent of alcohol by volume. Such beverages were exempted from the operation of the National Prohibition Act.

'In all, 45 of the 48 states have legalized the sale of alcoholic beverages in one degree or another. Kansas, Mississippi and Oklahoma are "dry" but all have legalized the sale of " 3.2 " beer.

For the primary features of various state systems, see Culver and Thomas, State Liquor Control Administration, A Statutory Analysis (1940). They report (20-2I) that 28 of the 45 wet states permit private sale of alcoholic beverages under state or local license. Seventeen states use the public monopoly for retail sale of distilled spirits. In seven of the license states control is centralized in the state government (Cal., Del., Conn., Ind., N. Y., S. C., Tex.). In New York and Texas the state agency is advised by local authorities but the power of decision is reserved to the state. In all of the monopoly states, except North Carolina, the operation of the monopoly is a state responsibility. In North Carolina, sale is permitted in those counties adopting the state store system by referendum. The county operates the liquor stores. Wisconsin and Minnesota authorize municipalitics to operate local package stores. The Delaware Liquor Commission is authorized to operate a monopoly of retail sale of distilled spirits or to license private package stores. The latter method has been followed. In Wyoming, the monopoly applies to wholesale rather than retail business.

"On-premise" sale of high proof liquors is prohibited in Arkansas, South Carolina and Texas among the license states. Of the monopoly states, nine (Idaho, Iowa, Mont., N. C., Ore., Utah, Va., Wash., W. Va.) prohibit such sales by the drink. For statutory provisions as of 1935 , see Harrison AND LAINE, After Repeal (1936) Appendix IV, Digest of State Liquor-Control Systems, 23I-248.

"Id. 63. Only nine license states issued "on-premise" licenses to premises approximating the old saloon. It appears that the monopoly states permitting sale by the drink restrict such sales to hotels,
} 
an incident to the serving of food, not as the primary object of the business establishment. More or less elaborate restrictions are placed upon the place where liquor is sold. These also vary considerably from state to state. In broad outlines they are aimed at the control of place location with respect to schools and churches, the maintenance of sanitary conditions, the limitation of the number of licensed places, and the maintenance of orderly conduct on the premises. ${ }^{8}$ Various states show interesting combinations of statutory rule and administrative discretion at these points of control. ${ }^{9}$

Due partially to a rather impatient demand for an early legal sale of alcoholic beverages, light beer and wines were declared to be legally "non-intoxicating," and in a number of states the sale of such beverages was legalized prior to the repeal of national and state prohibition. In some jurisdictions this separation of treatment has continued, based upon the assumption that the easy availability of low-proof and comparatively inexpensive drinks would soften the demand for the sale of high-proof and higher priced distilled spirits. In none of the monopoly states, for example, are light beer and wines included within the public monopoly, and in states where "onpremise" sale of distilled spirits is forbidden, beer may often be purchased by the glass at the corner drug store. ${ }^{10}$ For that matter, the sale of beer is seldom included in the "dry-area" restriction that may be assumed by local option.

\section{Patterns of State Control}

Three different types of emphasis are discernible in the activities of various state agencies concerned with liquor law administration. In general terms these represent primary concerns for revenue collection; for regulatory control through the use of enabling powers in the first instance and directing powers in the second; ${ }^{10 a}$ and for the proprietary operation of a state monopoly of spirituous liquors.

restaurants and clubs. Id. $148-149$. In the administration of the "on-premise" rcstrictions to bona fide eating places, lax supervision can readily permit the eating place requirement to degenerate to a symbolic compliance.

${ }^{8}$ No satisfactory compilation of statutory provisions has been discovered. Curver AND THOMAs, op. cit. supra note 5, at 49 , state that, of the 45 wet states, the state administrative agency controls hours of salc in 38 ; the location of licensed premises in 36; advertising in 35; the number of licensed places in 16 ; and the physical characteristies of licensed places in 27. Interesting examples of administrative regulations are Ohio, Dept. of Liquor Control, Reg. 5r; New Jersey, Dept. of Alcoholic Beverage Control, Regs. 20 and 2I; and Washington, State Liquor Control Bd., Rules and Regulations, tit. II.

${ }^{\circ}$ In connection with the exercise of regulatory discretion, see the broad grant to restrict amounts of purchases in Iowa Liquor Controu Act \$8(h), IOWA Code (1939) tit. VI, c. 93, and the regulation adopted by the Iowa Liquor Control Commission, Nov. 20, 1935, authorizing store managers to restrict the amount and the kind of liquor to be purchased by any purchaser. See also the authority granted to the New Jersey Commission of Alcoholic Beverage Control, N. J. Rev. Stat. (1937) 33: 1-39, and the regulations issued thereunder, particularly Nos. 20 and 21 covering the conduct of licensces, the use of licensed premises, equipment, signs and advertising matter.

10 "Non-intoxicating beer" may be purchased for on-premise consumption apparently cverywherc in the United States, unless prohibited by local ordinance. In six monopoly states (Idaho, Iowa, N. C., Utah, Va., W. Va.) the sale of beer is not supervised by the state administrative agency operating the monopoly but by the state revenue department.

$10 \mathrm{n}$ The use of the terms "enabling powers" and "directing powers" follows Freund. See Administrative Powers Over Persons and Property (1928) c. 4. Enabling powers impose conditions precedent to a course of action. Their excrcise by the granting of licenses, permits and similar authorizations cnables 
The first type, with the primarily revenue emphasis, often incorporates liquor control into the existing state agency for tax administration. In these instances, the enforcement of law against licensees is often a state concern, but the suppression of illegal sale is left to local police. The selection of licensees, within the limits of state restrictions, is likewise a local responsibility. In consequence deliberative functions at the state level are minimized in importance, and the form of the administrative agency is often that of a single administrator. ${ }^{11}$

In states placing a primary emphasis on regulatory control, taxes other than license fees may even be collected by an entirely separate department. ${ }^{12}$ The foremost task of the state agency is that of administrative regulation. In consequence importance is attached to such activities as the granting of licenses, the supervision of licensees, the exercise of discretionary directing powers in controlling the conduct of liquor sale, the investigation of complaints, the holding of formal hearings, the hearing of appeals from local action with respect to licensees or applicants for licenses, and the revocation or suspension of licenses. The organization of the state agency often reflects these deliberative and discretionary duties in multi-membered boards, and, in instances, the separation of administrative and deliberative functions. ${ }^{13}$

The monopoly states show further distinctive administrative characteristics. In each case deliberative functions bulk larger in the combination of proprietary management and regulatory control. The result is the use, in each of the monopoly states, of a multi-membered executive, alike in the emphasis of organization but differing substantially in the internal distribution of function and authority. In no instance, however, does the proprietary element stand alone. The dominating desire for effective regulation brings a parallel control over the licensing of "on-premise" sale, package stores supplementing state outlets, manufacturers, transporters, and venders

the person found qualified to proceed, but a person not so authorized is prohibited altogether from acting. Directing powers intervene in an authorized course of action to prevent abuses of the privilege. They are applied through administrative rules and orders, and may assume the external characteristics of a quasi-legislative or quasi-judicial method, or both. Thus through the enabling power, a person is licensed to operate a package store, but the continued exercise of the privilege is subject to regulation, beyond the scope of the conditions precedent, to prevent undesirable merchandising practices.

11 For present purposes, "revenue" emphasis is used to designate the institutionalization of liquor administration around existing state revenue collection. All of the states falling in this category are "license" states. States using the proprietary method, whether locally intended chiefly for profits or for control, are separately classified as "monopoly" states. Of the 28 license states, I2 have placed liquor administration in revenue collection agencies. In eight of these states the issuance and revocation of licenses appears to be either administered by local authorities or conditioned upon local approval or complaint. In nine of these states, law enforcement is vested primarily in regular police officers. Under these circumstances the state function tends to be concerned primarily with special matters. See CuLvER AND Thomas, op. cit. supra note 5 , at 54-63.

${ }^{12}$ In five of the license states (Conn., Ill., Mass., N. J., N. Y.) tax collection (other than license fees) is placed in the state revenue agency. It should be noticed that Massachusetts, New Jersey and New York represent the largest and in some respects the most difficult tasks of administrative regulation in the country. Culver and Thomas, op. cit. stupra note 5, at 35 .

13 There are 16 states that fall into this category. Seven use multi-membered agencies-three members in Conn., Ill., Mass., Neb. and Tex.; four members in Ind.; and five members in N. Y. For a classification of powers, see Culver aND Thomas, op. cit. supra note 5, at 50-52. 
of malt beverages. In some instances broad powers of law enforcement are also conferred upon the monopoly. ${ }^{14}$

The broad classifications of revenue administration, licensing control and public monopoly only designate the primary emphasis of state, as distinct from local, effort. In each instance the complete pattern of control must necessarily embrace all restraint and supervision imposed at every jurisdictional level within the state. Where, moreover, wide discretion as to the emphasis of action is left to the local community, a confusing diversity of practice can result. The term "monopoly," furthermore, identifies only the major characteristic of regulation in the states using the proprietary method. The monopoly does not exclude the use of regulatory licenses as to those phases of the liquor business that do not require the same extremity of restraint. Except for the retail sale of distilled spirits, the liquor industry is controlled with few exceptions by the licensing method.

Within the general patterns of state regulation there exists the widest range of individual differences in method and emphasis. Perhaps the most significant feature, common to most of these varying systems, is that few are based upon rigid statutory provisions. For the most part, the statutory rule is stated in general terms and leaves to administrative discretion the intricate task of fitting detailed restrictions to the practices of the regulated industry. There results a fringe of experimental restraint built primarily with administrative powers. At this front line of public regulation, the ebb and flow of changing policy is most likely to appear. As public values change or pressures accumulate in the regulated industry, the point of first impact is apt to be the administrator's office from which detailed regulations and instructions issue. In consequence it seems not unlikely that the shifting and turning of policy that Freund noticed throughout the history of liquor regulation, if continued, will be located in the future at the level of administrative legislation where changing pressures can be absorbed without the formality of statutory amendment. ${ }^{15}$ This more

${ }^{14}$ Sixteen states operate a state monopoly of retail package sale (Ala., Idaho, Iowa, Me., Mich., Mont., N. H., N. C., Ohio, Ore., Pa., Utah, Vt., Va., Wash., W. Va.). Wyoming's monopoly is of wholcsale sale. The Delaware department is authorized to operate either a monopoly or licensing system. The latter alternative has been used but orders are placed by retailers through the state department. Each of the state agencies uses a multi-membered board of three members except in Ohio (four) and in Wyoming (five). Michigan and Wyoming boards include elective state officers as ex officio members. See Curvrr AND Thomas, op. cit supra note 5, at 22-24.

${ }^{15}$ In this connection it is interesting to consider the entire footnote of Freund, supra note I: "The history and present operation of liquor legislation reveals also very clearly the practical limits of the police power; the futility of extreme measures antagonizing the habits of many people and the demoralization incident to the administration of unenforceable laws. There is hardly any other branch of law in which there has been so much shifting and reversing of policies. All forms and methods of governmental powcr have been tried, and have as a rule been found successful in the inverse order of their incisiveness. Prohibition is the least efficient policy; restrictive regulation with discretionary powers is less efficient than restrictive regulation without discretionary powers; governmental regulation is not as cfficient as social pressure, social pressure is not as efficient as the slow education of public sentiment, and nothing is so efficient as the supplanting of the attractions of drink and of the saloon by providing other sources and forms of rational pressure." $O p$. cit. sipra note 1 at $193-194$, n. 2. Freund's reference to discretionary powers was in terms of local control since the use of well-developed state regulatory powers had not yet come about. There is some evidence that the broader base of administrative regulation at the state level, 
flexible method of regulation may in the long run produce a better stabilized and on the whole more effective public control.

\section{The Licensing Method}

The use of enabling power as a method for the regulation and restraint of the liquor business has a long historical background. ${ }^{16}$ In mechanics the device is exceedingly simple. The doing of business without the authority of a license or permit is expressly forbidden and is a crime. Licenses or permits are issued for limited periods, ordinarily one year, and are not automatically renewed. Such restrictions as seem appropriate are attached usually by statute as conditions precedent to application for the license or permit and others of a more discretionary nature as conditions of the continued enjoyment of the privilege. Such conditions may relate both to the person applying, and to the place where the license is to be exercised. ${ }^{17}$ In addition, the number of licensees may be limited directly by a ratio to population in the local jurisdiction, or indirectly by a high license fee. The list of licensees furnishes a directory for inspection and investigation, defines the regulated group, and lays the groundwork for continuing supervision. Enforcement is accomplished by the revocation of the license, a suspension for a period of time, or by a refusal to renew after the expiration of the license term.

In terms of administrative mechanics the use of enabling powers calls for a process using a deliberative method but equipped with a specialized field force policing the regulated group. Where broad statutory discretion permits the administrative imposition of terms and conditions upon licensees, a deliberative method is required for the setting up of standards. In any case a decision must be made as to whether the license shall or shall not be granted, whether a license should be renewed, and whether administrative penalties should be imposed and, if so, of what severity. Auxiliary to these functions may be policing, accounting, clerical and routine legal operations.

Of the 28 states using the licensing method of alcoholic beverage control, eight were chosen for special analysis. ${ }^{18}$ These were selected as representative of the principal types of administrative organization, regulatory method and distribution of authority between state and local authorities. In addition they reflect work loads of from some 462 licenses and permits in Delaware to 72,655 of all kinds in New York state. ${ }^{19}$ Their total population aggregates approximately 40 million persons.

with a specialized agency and developing technical procedures, may provide a more effective method of control.

${ }^{10}$ For the best discussion of enabling powers see FREUND, op. cit. stspra note 10 ${ }^{a}$, at 104-139, 49 I-498.

${ }^{17}$ For an excellent illustration of these conditions in statutory form, see N. Y. Alc. BEv. Cont. LAw, art. $4, \S \S 54,55$; art. $5, \S \S 63,64$; art. $8, \S \S 100$ et seq. These are explained infra p. 610 .

${ }_{18}$ The states analyzed are Cal., Del., Ind., Mass., N. J., N. Y., Tex., Wis.

${ }^{10}$ Delaware as of Dec. I, I939, Del. Lie. Cont. Coms., Rep. (1939) pt. II, 3. New York, issued during 1939, N. Y. Alc. Bev. Aurf., Rep. (1939) 16-r7. 


\section{Characteristics of Licensing Agency}

The states selected for analysis show an impressive diversity in administrative characteristics. In California control is entirely centralized in the state to the exclusion of all local action including the privilege of local option. ${ }^{20}$ Wisconsin, on the contrary, leaves the licensing and regulation of the retail sale of liquor to local authorities. The state performs only revenue collecting operations. ${ }^{21}$ Between these extremes are many intermediate stages. In New Jersey, a separate and essentially independent administrative establishment was created headed by an administrator named in the statute, while in California the function of liquor control was delegated to the popularly elected State Board of Equalization. In Delaware in the terms of the statute the "... Commission shall consist of only one (r) member. ..."22 New York is at the other end of the scale with a five-member authority.

A closer examination of the internal organization of state liquor agencies reveals a number of interesting adaptations. The Wisconsin statute specifies the method of control but merely provides that certain types of licenses shall be obtained from the state treasurer. ${ }^{23}$ The exercise of this power of the state treasurer was placed by him in a beverage tax division of his office which was subsequently, in 1938, transferred to the Wisconsin Tax Commission where the division became a unit within the Excise Division of the commission. Inspection and enforcement operations were separated from the beverage tax unit and assigned to a departmental inspection and enforcement bureau. ${ }^{24}$ Under its present authority and organization, state liquor control in Wisconsin thus appears to be a comparatively subsidiary interest of a large administrative agency. Revenue collection and enforcement seems to dominate the state's effort.

In California state control was also placed in a state fiscal agency, the State Board of Equalization, where it became only one of seven major concerns. The state constitutional amendment, however, centralized all control powers at the state level. ${ }^{25}$ It appears that the State Board of Equalization has not exercised its powers with a restrictive emphasis; that board members have divided up the area of the state for individual control; and that widespread dissatisfaction has accumulated. Late in I939 two members of the board were indicted as the result of a grand-jury investigation of a reported liquor license racket. ${ }^{2 B}$

\footnotetext{
${ }^{20}$ For an excellent discussion of the California experience, see Curver and Thosas, op. cit. stipra note 5, at 12-19. The California statute is Alc. BEv. Cont. Act, Cal. Stats. I935, c. 330, as amended by Cal. Stats. I937, c. 758 . 21 Wis. Stat. (1939) c. $176, \$ 54-14$

${ }_{22}$ Del. Rev. Code (1935) c. I76, \$6133, \$4(I). N. J. Rev. Stat. (1937) tit. 33, \$I-3 provides: "The chief executive of the department shall be the state commissioner of alcoholic beverage control. . . . His term shall commence upon the sixth day of December, one thousand nine hundred and thirty-three, and shall terminate on the first day of April, in the year one thousand nine hundred and forty, but he shall serve until his successor has been elected and qualified. His successor shall be elected by a joint session of the legislature for a term of seven years beginning on the first day of April, one thousand nine hundred and forty, and every seven years thereafter. . . . The first state commissioner of alcoholic beverage control shall be D. Frederick Burnett of the village of South Orange, in the county of Essex. . . ."

${ }^{23}$ WIs. Stat. (т939) c. I76, \$5.

${ }^{25}$ Culver and Thomas, loc. cit. supra note 20.

${ }^{24}$ Wis. TAx Comm., Bien. Rep. (r938) 32-38.

${ }^{20}$ Ibid.
} 
Both New York and Massachusetts have created special state agencies for control purposes. In Massachusetts, a three-member commission is a separate state department while in New York the five-member authority is a division of the Executive Department. It appears, however, that the New York authority is to all intents and purposes an independent agency. In neither state is there a statutory indication of a separation of function between the controlling body, its chairman, or between the body and its subordinates. A suggestion that the chairman of the body in each state is expected to perform additional services is found in the Massachusetts provision that he shall receive a salary of $\$ 7,500$ against $\$ 7,000$ for the other members; and in New York that he shall receive $\$ 12,000$ as compared with $\$ 7,500$ for the other four members. ${ }^{27}$

Texas and Indiana, however, have taken further steps in the separation of administrative functions. Both states use a board for certain purposes. In Texas a threemember board receives a per diem of $\$$ io for not to exceed 60 days of each year. An administrator is appointed by the board to serve at its pleasure. He receives an annual salary of $\$ 6,000$. The statute grants certain powers to the "Board," and others to the "Board or administrator." It is also provided that concurrent powers of the board and administrator shall be exercised as the board may prescribe. The administrator performs his duties under the supervision of the board. ${ }^{28}$

The Indiana agency is a division of the executive department and consists of an excise administrator and an alcoholic beverage commission of three members. The administrator acts as chairman of the commission. All are appointed by the governor who also fixes their compensation at not more than $\$ 6,000$ a year. The statute grants powers separately to the commission and to the administrator. The former grants or refuses licenses; revokes them; adopts and promulgates regulations; and prescribes procedures to be used by local boards. The latter is executive officer of the commission and administers the alcoholic beverage division. ${ }^{29}$

\section{Interrelation of State and Local Control}

Traditionally the licensing of retail liquor establishments rested with local authorities, in some states municipal or county governing bodies and in others the inferior court of record. The prohibition movement, the increased emphasis on state taxation and the demand for centralized and more stringent controls led plausibly to a large state part in the process of control. The combined result of tradition and new pressures have produced many interesting combinations of state and local authority. These range from completely centralized state control; through local advice and consultations, formalized local recommendation, a division of regulatory jurisdiction; to complete local supervision. A few samples will illustrate the types.

California, for example, centralizes all types of control at the state level. Practice, however, has brought about a degree of consultation with local officers before licenses

${ }^{27}$ Mass. Gen. Laws (1931) c. 138; N. Y. Laws 1934, c. 478 , as amended.

${ }^{28}$ Texas Liquor Control Act, Vernon's Tex. Stat. (I936) Penal Code c. 6, art. 666, §iz(b).

${ }^{20}$ Ind. Acts 1935 , c. 226, as amended by Ind. Acts 1937 , c. $197, \$ 6$. 
are granted. Routine law enforcement is left to local police. ${ }^{30}$ Texas makes specific provision for consultation with local officials and requires that the state board give "due consideration" to their recommendations. ${ }^{31}$ In Indiana and New York special local authorities have been created. Local control boards in Indiana are composed of three members-a representative of the state commission, a member appointed by the county commissioners and one appointed by the mayor of the largest municipality in the county. Provision is made to assure representation upon the board of municipalities of over 10,000 population when applications relating to premises within such places are considered. Members receive a nominal compensation. The local board is required to investigate applicants for permits and to report upon the propriety of issuance. The function is entirely advisory. ${ }^{32}$

In New York a local alcoholic beverage control board is used in each county except for those within the city of New York. The boards consist of two membersone appointed by the state liquor authority and the other by the county board of supervisors from a list of eligibles submitted by the governing body of the county medical society. A special board for New York City is composed of four memberstwo appointed by the state authority and two appointed by the mayor on nomination by the executive bodies of the Academy of Medicine, and the Merchants' Association and the Central Trades Labor Council. Members of the New York City board receive an annual salary, but members of county boards are compensated on an annual fee basis. The boards are authorized to recommend the issuance or refusal of retail licenses and the revocation of such licenses; to investigate and take testimony, and, except in New York City, to restrict the hours for retail sale. Provision is made for a staff to serve each local board. All expenses are paid by the state. ${ }^{33}$

Retail licensing in New Jersey is largely administered by local authorities. The local licensing authority determines in the first instance whether the license should be issued. An applicant, or any other person aggrieved by the action of the local board, may appeal to the state commissioner. The local authority may also stipulate the conditions of a license, but these are subject to the commission's approval. Suspension or revocation may also be made by the local body subject to appeal to the state commissioner. ${ }^{34}$ Of particular interest is the provision that municipal action limiting the number of licensees or hours of sale may be appealed to the state commissioner who "... after public hearing, may set aside, vacate and repeal the limitation complained of or change, alter, amend or otherwise modify the same."35

${ }^{30}$ Culver and Thomas, op. cit. supra note 5, at 17, discussing provisions of Cal. Stat. 1937, c. 758.

${ }^{31}$ Tex. Lip. Cont. Acr, supra note 28, \$12(a).

${ }^{32}$ Liquor Control Act, Ind. Acts 1935, c. 226 as amended by Ind. Acts 1937, c. 197, 56.

${ }^{33}$ N. Y., Alc. Bev. Cont. Law (1934) c. 478, art. 3.

${ }^{34}$ In all municipalities under 15,000 population, except in 6 th class counties which are Ocean and Cape May, local governing bodies are licensing authorities. In municipalitics over 15,000 , the governing body may establish a special three-man municipal control board. N. J. Rev. STAT. (1937) tit. 33, \$\$1-5, 1-I9. In 6th class counties, licenses are administered by the judge of the court of common pleas. Id. tit. 33 , $\$ \mathrm{I}-2 \mathrm{I}$, as amended. In municipalities over 100,000, moreover, having a board of finance, the board may establish a municipal excise commission which exercises local powers of control within the municipality. N. J. Laws 1940, c. 63 .

${ }^{8 E}$ N. J. Rev. Stat. (1937) tit. $33, \$ \$ 1-41$. 
Under the Massachusetts law, local licensing authorities grant or refuse retail licenses subject to appeal to the state commission. Local disciplinary action is subject to a similar administrative appeal. Local taxpayers may intervene to question local action by filing a "remonstrance" with the commission which is treated as an appeal from the action complained of. ${ }^{36}$ Wisconsin stands at the end of the scale in local authority. Under the licensing system used in that state, all authority over retail licensees, with limited exceptions, is exercised by local governing bodies, and appeals from local action are heard by the courts. No administrative appeal is used. ${ }^{37}$

\section{Characteristics of Administrative Authority}

The authority granted to licensing agencies in the jurisdictions examined shows further interesting aspects. The draftsmanship of the Texas Liquor Act, as amended, reflects a definite concern for stabilized administrative action. It is provided, for example, that a rule or regulation to which a penalty applies may be adopted by the state board only after published notice and public hearing. At the hearing any interested person is entitled to be heard. ${ }^{38}$ After adoption the rule or regulation is published. Disqualifications of applicants for licenses or permits and grounds for the suspension or revocation of licenses, moreover, are specified in detail. The activities authorized by the possession of a license or permit are likewise set out with care. ${ }^{39}$

Indiana legislation requires that the state board shall investigate the fact situation before adopting a rule or regulation and conditions the exercise of the rule-making power upon the reaching of any one of five conclusions of fact. The conditions are so generalized as to be of little apparent value in controlling administrative action. ${ }^{40}$

Of the states examined New Jersey shows the broadest administrative discretion in the state commissioner. That officer is authorized to "make such general rules and regulations and such special rulings and findings as may be necessary for proper regulation. . .." A list of subjects follows in such general terms as "sales on credit," "out-of-door sales," "use of screens," and "practices unduly designed to increase consumption of alcoholic beverages." An examination of the regulations promulgated reveals a statutory form and detail that is close to legislative treatment in other states. ${ }^{41}$

While the Wisconsin statute uses few administrative restrictions, it contains a unique provision for the banning of retail sale to certain persons. Any person who by excessive drinking exposes his family to want or the local jurisdiction to liability for his care may be banned from purchases for the period of a year by the signing of a statement to that effect by the person's wife, the governing body, or certain other specified local and county officers. The selling of liquor to such a "black-listed" person is a criminal offense. ${ }^{42}$

${ }^{30}$ MAss. Gen. Laws (1931) c. $138, \$ 67$.

${ }^{37}$ WIs. STAT. (1939) c. 66, \$5; c. $176, \$ \$ 5(1)$, II-12.

${ }^{38}$ TEX. LIQ. ConT. ACT, stipra note 28 , at $\$ 7(a)$.

${ }^{30} I d ., \S \S \mathrm{Ir}, 12,15$.

${ }^{10}$ LiQ. Cont. Act, supra note 32.

${ }^{2}$ N. J. Rev. Stat. (1937) tit. 33 II-39. Cf. Regulations Nos. 20, 21, 22, 23.

$\$ 2$ Wis. Stat. (1939) c. 176, \$26. 
An integrated picture of the operation of the licensing method may be secured by examining the provisions of the New York statute. ${ }^{42^{a}}$ In that state a person desiring to operate a business selling alcoholic beverages by the drink will find that standards apply to the place of sale as well as to the vendor. He cannot qualify as an applicant unless he is operating a bona fide restaurant, hotel or club. (For the purposes of this illustration the club license will be excluded.) The premises, however, must not be within 200 feet of a building situated on the same street that is used exclusively as a school, church or other place of worship. But this requirement does not apply if the hotel or restaurant premises were used for those purposes prior to December 5, 1933. The applicant must either own the premises or have them under lease for the period of the license. If, however, a license granted to a business at the same premises was revoked during the two years preceding, the applicant runs the risk that the state liquor authority might refuse to grant a new license. If the premises are a restaurant there shall be no curtains or screens preventing a clear view of the interior from the sidewalk, no swinging entrance door, no interior partition obscuring a full interior view, and no entrance to abutting premises. All glass windows, moreover, must be of clear glass.

The applicant himself must be a citizen over $2 \mathrm{I}$ years of age and never convicted of a felony. If he was previously a licensee whose license was revoked in the past two years, he is automatically disqualified. If while not a licensee, he was convicted of a violation of the liquor control act during the preceding two years, he is also disqualified. If, moreover, the applicant is a copartnership, all partners must meet the requirements for individual applicants; and if a corporation is applying, all offcers of the corporation must be qualified. A manufacturer or wholesaler of alcoholic beverages must not be interested in the business, and the applicant must not be interested in any manufacturing, wholesaling or other retailing business in such liquors.

Application for the license is filed with the local board for the county (unless the premises are within New York City). The forms prescribed by the state authority must be filled out completely and the fee must be paid with the filing of the application. The local board investigates the applicant and the premises and forwards the license application and the fee with its recommendations to the state authority which may either grant or refuse the license. A hearing, if requested, may be held and each body must reach its decision within a 30 days' period. If the authority decides to grant the license, it may require a bond conditioned upon the maintenance of proper conditions on the premises. When the license is received, the proprietor must place it prominently in the premises.

After the business has gotten under way, restrictions apply to sales, employees, premises, and financial operations. No sales may be made to persons under I8, drunkards, or persons intoxicated. Hours of sale are from eight in the morning until

\footnotetext{
${ }^{42 a}$ This material drawn from the following sections of the N. Y. Alc. Bev. Cont. LAw: 54, 64, 65, 99, I00, I01, 101-a, 102, 104-a, 106, 108, I10, 112, I13, 114, 118, 119, 120, 121, 126.
} 
three the next morning (four in New York City) unless the local board fixes earlier closing hours. It is not necessary that food be purchased with liquor. No credit sales are permitted except by hotels to registered guests. The licensee may not sell for consumption off the premises. As to employees, any who handle or serve alcoholic beverages must be over I8 years of age. The licensee shall not knowingly employ any person who has been convicted (unless subsequently pardoned) of carrying illegal weapons, possessing burglar's tools, possessing narcotic drugs, or vagrancy, among other stipulated offenses.

The premises must be maintained in the condition required for the issuance of the license. No signs advertising a particular brand of beverages shall be shown, and no signs whatever, without prior consent of the state authority. No gambling shall be permitted on the premises. The place shall, in addition, be subject to inspection by any authorized officer at any time when open for business.

On the financial side, the licensee shall not accept or extend a loan from or to another licensee. There are stringent restrictions upon his credit with wholesalers and distributors. In addition he must keep the books and other financial records required by the authority.

The state authority may revoke, suspend or cancel the license "for cause," but it is required to revoke if there is a conviction for illegal sale on the premises, a false statement in the application, the license is transferred or assigned, the premises cease to be a bona fide restaurant or hotel as the case may be, or for failure to file a required bond or pay the tax.

Opportunity for hearing is given in the administrative proceedings. Judicial review of the revocation may be heard by the supreme court.

\section{Trends in Administrative Action}

The analysis of available data provides little basis for the appraisal of state liquor control exercised through the licensing method. It may be significant, however, that in Massachusetts the number of appeals from decisions of local licensing authorities has steadily decreased. Appeals taken from local refusals to license, for example, have fallen from 860 in 1934 to 248 in 1938 , and the proportion of appeals sustained has fallen from some $30 \%$ in 1934 to about $15 \%$ in 1938 . Remonstrances filed by local taxpayers numbered $x_{5}$ in 1934, and dropped to four in 1935 . In 1936 and 1937 none was filed while in $193^{8}$ one was entered but was dropped before hearing.43 This trend may well indicate a maturing of the administrative process with its operation increasingly less open to complaint.

The New York authority shows, out of 99x license proceedings in 1939, 340 suspensions, 59 revocations, 298 warnings and $\mathrm{I} 4 \mathrm{I}$ charges dismissed. Other proceedings were disposed of by some variety of disciplinary action so that in 552 of the cases considered some punishment was administered. Data on the judicial review of disciplinary action show very few applications for judicial review in proportion to

${ }^{13}$ See Mass. Alc. Bev. Cont. Comm., Ans. Reps. I934-r938 inc. (Pub. Doc. No. I53). 
the total number of actions undertaken. ${ }^{44}$ From the disposition of administrative proceedings in Texas it appears that some disciplinary or restrictive action was taken in all but 3 II of the 2826 cases heard by the state administrator during $1939 .{ }^{40}$

From these data it appears that regulatory control is at least at work. Whether it is coping with the problems existing in the regulated community depends upon a number of factors that are not within the reach of this inquiry. In the last analysis the standards existing in that community determine the level of public effort which in turn confronts resistance, avoidance and noncompliance. The appropriateness of the administrative mechanism and its procedure for the performance of its work assignment can be determined only by a continuing and exhaustive analysis.

\section{The Monopoly Method}

From the standpoint of regulatory method the most significant development in post-Repeal liquor control was the establishment in seventeen states of some form of public monopoly of the sale of distilled liquors. This movement was not without precedent among the states, but it seems doubtful that the South Carolina dispensary system or any similar state effort strongly influenced the drafters of new monopoly statutes. More immediate influences were the monopoly system of several Canadian provinces, the Swedish method of control and the deep-seated reluctance to see the liquor business back in private hands, where, it was feared, the profit motive might defeat effective public control. It is of no little significance that the states adopting the monopoly system were either close to the Canadian border-Michigan, Ohio, Vermont, New Hampshire, and Washington, among others-or had been predominantly dry with repeal winning only by comparatively slight margins-as in Virginia, West Virginia, North Carolina and Alabama. ${ }^{46}$

From the administrative standpoint, the monopoly method calls for a unique combination of operating activities. The proprietary function requires all of the mechanism of large scale merchandizing but simplified considerably because sales promotion is neither necessary nor socially desirable, the products sold are standardjzed and do not require diversified handling, and the strategy of customer appeal in store premises and equipment is unnecessary. Nevertheless there still remain the important responsibilities of large scale stock purchasing, inventory and sales control, personnel supervision and financial management. These requirements are unknown to the licensing method. As administrative powers, they can be classed only as noncoercive with respect to the community. Compulsion is entirely a matter for internal discipline. Coercive powers are used only for the control of the purchaser and his conduct in the state store.

\section{Nature of the Monopoly}

The monopoly method applies primarily to the retail sale of distilled spirits. These are the high-proof beverages that are generally assumed to be the primary root of

"4 N. Y. State LiQ. Auth., Rep. 1940 (Leg. Doc. No. 50) 83-84.

${ }^{5}$ TeX. Liq. Cont. Bd., ReP. (1939) I 8-24-

${ }^{\circ}$ See Harrison and Laine, After Repead (1936) 107 et seq. 
social abuse. Wines and beer are another matter. So-called "non-intoxicating" beverages, however defined in the local jurisdiction, are invariably beyond the monopoly. In most cases all wines and beer are treated in this same way although in some states the monopoly handles "heavy" wines and beers. Not only are such beverages usually viewed as needing less stringent control, but also the problem of handling bulk sales, such as beer by the case, is of considerable moment. ${ }^{47}$ Monopoly systems usually include wholesale business in distilled liquors and heavy wines, but this is important only where sale for on-premise consumption is permitted. Wyoming operates a wholesale monopoly only. Several states are authorized to manufacture alcoholic beverages for sale through the store system, and some experimentation has been undertaken in the state bottling of liquors purchased by the barrel and sold under state brands. ${ }^{48}$ Such products have never represented a large proportion of sales volume although retail prices are substantially lower than for private brands.

Beyond the limits of the monopoly method are other phases of the liquor business. These include private manufacture for sale outside the state, transportation of alcoholic beverages through or out of the state, the regulation of "on-premise" sale where permitted, and law enforcement. The monopoly method permits an additional control over "on-premise" sale since retailers can be required to purchase all stocks by or through the monopoly thus tending to assure quality, stabilize price and check sales volume. Apart from this added check-rein, manufacture, transportation and sale are regulated in the monopoly states by the same methods found in the license jurisdictions. The issuance of licenses or permits enables approved persons to operate at approved premises. Substantially the same conditions precedent are imposed and subsequent control is applied by the same types of directing power. Enforcement activities are concerned with the behavior of licensees, the operation of unauthorized persons and the protection of the monopoly.

The span of proprietary, regulatory and enforcement activity is coordinated by personnel management, fiscal supervision, the administration of properties and equipment, and special treatment of legal questions. In brief, an adequate monopoly system calls for a well-developed administrative organization in which the operations of business management, rule-making and administrative adjudication are all important. The breadth of these responsibilities has some tendency toward a division of internal operations making coordination difficult and complicating the task of executive direction. 49

For present purposes the operation of monopoly systems was examined by sampling seven of the seventeen states using that method of control-Pennsylvania, Vir-

${ }^{47}$ The Ohio monopoly system applies only to "spirituous liquors" defined as containing not more than $7 \%$ alcohol by weight or $21 \%$ alcohol by volume. Lrovor Control Act, Ohro Gen. Code (I938) $\$ 6064(\mathrm{r})$. Beer and wine are excluded by Michigan. Liquor Control Law $\$ 3$, Comp. Laws Mich. (Mason's Supp. 1940) $\$ 9209$ (16-73a). The West Virginia monopoly includes all beverages containing more than $5 \%$ alcohol by weight. W. VA. CODE (1937) c. $60, \$ 5907(60,61,65,67)$. No beer is stocked by state stores in West Virginia.

${ }^{68}$ Washington, Ohio and West Virginia authorize various types of "state brands." See infra note 64 .

"See also the discussion in Harrison and Laine, loc. cit. stupra note 46. 
ginia, West Virginia, Ohio, Michigan, Iowa and Washington. These states sold some $83 \%$ of all of the alcoholic beverages marketed by monopoly systems in 1939.50 They represent, consequently, the most active systems in the county. On the other hand several variants of the monopoly method, while interesting, are not included. Wyoming, as has been pointed out, restricts its monopoly to wholesale business. Alabama provides for a state-administered monopoly but stores may be established in a county only after a favorable vote in the area concerned. Most of the area of North Carolina is dry, but any county may by referendum elect to install a system of county stores which operates under state supervision. ${ }^{51}$ Several Maryland counties, outside of the city of Baltimore, operate county dispensaries. In both Minnesota and Wisconsin municipalities may and do operate municipal stores. None of these special systems do a sufficient volume of business, nor are they territorially sufficiently comprehensive to justify extensive treatment.

\section{Administrative Organization}

The monopoly states, altogether, show different degrees of control which for present purposes can be summarized in three categories. First, there is the class of states that permit "on-premise" sale by licensees who have purchased their stock by or through the monopoly. Pennsylvania, Ohio and Michigan fall into this group. Second, there are states that do not permit the sale of distilled beverages for "onpremise" consumption. Virginia and West Virginia are in this class. The former, however, permits the sale of heavy wines and beer, while the latter forbids the consumption in a public place of any "intoxicating" liquors. The third type represented by Washington and Iowa restrict the purchaser at state stores by requiring individual permits to buy.

All of the monopoly systems are administered by multi-membered boards, and all are established as separate state departments. There are, however, interesting variations in the form of the departmental executive. In two states, elective state officers are ex officio members of the administrative board. These are Wyoming and Michigan. In the former state such officers compose the entire membership of the control board, while in the latter they are a minority of the membership. ${ }^{62}$ In Wyoming the $e x$ officio body acts through a director, but in Michigan a quite different method is used. In that state the liquor control commission consists of five members-the governor and secretary of state, ex officio, and three additional members appointed by the governor with the advice and consent of the senate. The appointed members are required to devote their entire time to the duties of their office. One of their number is chairman. A quorum consists of one ex officio member and two appointed

\footnotetext{
${ }^{50}$ I939 sales are reported by Distilled Spirits Institute, Public Revenues from Alcoholic Beverages 1939 (1940).

${ }_{61}$ Ala. Beverage Controt Act, Ala. Acts 1936-1937, No. 66. N. C. Code (1939) c. 66.

${ }^{52}$ Wyoming members are the governor, secretary of state, and state treasurer. Wro. Rev. STAT. (Supp. 1940) c. 59 , art. 4,840 r.
} 
members, but an ex officio member may act through a deputy and in consequence actual participation by the state officer is not necessary. ${ }^{\mathbf{5 3}}$

As a general rule, administrative authority is granted to the control board without distinguishing among the various functions involved in the control process. Various adaptions have occurred from state to state. In Pennsylvania, for example, it appears that the board acts in a collegial capacity with operating divisions in immediate control of directors. In West Virginia the practice has been for the chairman to assign operating divisions to the various members for immediate supervision. In Virginia a similar distribution of supervision has been used. In both instances quasi-legislative, quasi-judicial and monopoly policy decisions are reserved to the commission as a whole. In West Virginia, however, the chairman, who is named by the governor, has at times assumed a dominating role in commission affairs that relegates his associates to the position of administrative subordinates.

Only one of the states examined shows a carefully planned separation of function between the state control board and a separately appointed director. That state is Ohio, where the internal organization of the department of liquor control strongly resembles that of the Civil Aeronautics Authority under the Civil Aeronautics Act. $^{54}$ The Ohio agency consists of a board of four members and a director of liquor control. All are appointed by the governor with the advice and consent of the senate, but the members serve for four year terms while the director holds office during the pleasure of the governor. As powers are distributed between the board and the director, the latter, in contrast to the situation found in most states, is by far the most important officer of the department. The board adopts all rules and regulations except those relating to the management of state liquor stores. It also fixes prices for the sale of liquor at state stores, imposes diciplinary action upon permittees and hears appeals from the department. The director administers the affairs of the department, grants or refuses permits, manages the store system and enforces the liquor law. ${ }^{\mathbf{5 5}}$

The span of activities embraced within state monopoly agencies depends largely upon the type of control used. Iowa, West Virginia and Washington are illustrative of states where the spread of responsibility is relatively narrow. In both Iowa and West Virginia the control of "non-intoxicating" beer is relegated to a separate state administrative agency. ${ }^{56}$ In neither state is "on-premise" sale of distilled liquors permitted. In both, wholesale sale to special permittees is through the state monopoly. In consequence the administrative task is limited to the operation of the state store system, the licensing and regulation of manufacture and transportation, and the

${ }^{53}$ Lie. Cont. LAW \$5, supra note 47.

"toho Gen. Code (1938) $\$ 6064$ (2-8 incl.). Cf. Civil Acronautics Act, 52 Stat. 980-986 (1938), 49 U. S. C. $\$ \$ 42 I-458$.

${ }^{65}$ Appeals from decisions of the director regarding permits may be taken to the board. In 1939, 1350 applications were rejected and 734 appeals from these actions were taken. The department was sustained in 292 and reversed in 442 instances. In view of the large number of reversals, it should be noted that the department rejected many applications so that a full hearing might be had on appeal at which all parties could be heard. Ohio Dept. Lie. Cont., Ann. Rep. (1939) ir-i2.

${ }^{50}$ In Iowa, the state treasurer's office; in West Virginia, the state tax commissioner. 
enforcement of the state law. The Iowa commission, moreover, relies largely upon local enforcement officers. In Washington the control agency licenses and regulates the retail sale of beer, but "on-premise" sale of distilled beverages is banned.

A state occupying a rather intermediate position is Virginia. There "on-premise" sale of distilled liquor is prohibited but the sale of wine and beer is licensed. In consequence the Virginia alcoholic beverage commission has a broader span of authority measured by the responsibility of retail licensing, supervision of licensees and diciplinary action with attendant quasi-judicial functions. ${ }^{57}$

The broadest span of responsibility and most complex combination of powers is found in the three states of Pennsylvania, Ohio and Michigan. In these states "onpremise" sale of distilled liquors is permitted. In consequence the state control agency has the responsibility of administering the licensing control of on-premise consumption in addition to the management of state stores (and in some instances subsidiary retail outlets) and the enforcement of the control law. These three states represent the widest administrative responsibilities found in any of the state liquor control agencies. The Ohio department of liquor control, for example, manages 204 stores and 58 agencies selling $\$ 51,696,000$ of alcoholic beverages during $x 939$. On the side of regulatory control, 29,426 permits of 22 different types were issued during the same year. Administrative proceedings involving violations of law and departmental regulations on the part of permittees numbered 1052. Fiscal operations included the handling of proceeds of sales, the purchase of stocks to the value of some $\$ 33,000,000$, the remittance to the state treasurer of nearly $\$ 7,500,000$ in state gallonage taxes, and the distribution of some $\$ 5,750,000$ in permit fees to local subdivisions. Enforcement activities showed 2152 raids and 2098 arrests during the year. The operations were administered by a full and part-time personnel averaging 1428 persons at a total expenditure for the year of $\$ 3,622,000$. $^{58}$ These data indicate the total work load of the department and its approximate distribution over the span of different administrative operations.

As a general rule the monopoly states show a much greater concentration of control authority at the state level than do the license states. Iowa and Washington rely heavily upon local authorities in the enforcement of law, but only to a minor extent does this involve questions of administrative policy or action. In Virginia the local subdivision may require a license of a person holding a state license or permit. ${ }^{50}$ Maximum amounts are set for local fees by state law. It appears that these local licenses are fiscal rather than regulatory in character. Michigan is the only state examined that contemplates a local regulatory control and in that instance the state commission is required to revoke a license for "on-premise" sale when so requested by a local legislative body. ${ }^{60}$

67 Alcoholic Beverage Control Act (1934) \$\$18, 25, VA. Code (I936) \$4675 (I-90).

${ }^{68}$ See the impressive ANN. Rep. (1939) passim. ${ }^{50}$ Ar.c. Bev. ConT. Acr \$26, stlprat note 57.

${ }^{\circ 0}$ This requirement applies only to counties under 500,000 population, Lio. Cont. LAw \$17, supra note 47 . 


\section{Operation of the Monopoly}

Thus far the discussion of the monopoly states has considered the general scope and characteristics of the proprietary method, the forms of administrative organization found in state monopoly agencies, the span of administrative responsibilities, and types of relations with local jurisdictions. Attention now turns to the operation of the monopoly method and its characteristics in the several states examined.

It has been pointed out above in this discussion that each state using the monopoly method also employs enabling powers for the regulation and control of those phases of the liquor business falling beyond the proprietary method. This regulatory side of the monopoly method varies in importance from state to state depending primarily upon the degree to which "on-premise" consumption of distilled beverages is permitted. In any case, the use and operation of licensing powers does not differ from the practice of the licensing states. Conditions precedent to the granting of licenses, the application of restriction to licensees, and disciplinary methods and penalties are all substantially the same. ${ }^{61}$

The state liquor monopoly is one of distribution and as such it reserves to the state the sale of beverages at wholesale and retail. Manufacturing as such is not within the monopoly but in some states the monopoly is authorized to market its own brands of liquors in the expectation that advertising and similar costs can be eliminated and retail price materially reduced. State control agencies in Washington and Ohio are authorized to purchase beverages in bulk and to bottle them for retail sale. ${ }^{62}$ This process includes rectifying. West Virginia authorizes its state commission to contract for the production of liquors to bear special "state brands." 63 Of these states Washington is the only one that appears to have made extensive use of its powers. Early in the history of the Washington Liquor Control Commission experiments were begun with the importation of Scotch whiskey and the purchase of California wines in bulk. Later Canadian whiskey was added to the list of state brands. This activity has developed until, during the year ending September 30 , r939 more than I30,000 cases of beverages were bottled, a business aggregating \$720,688 of which $\$$ II8,588 represented the profits of the bottling plant. State bottled brands, however, amounted to only some five per cent of the total sales at state stores in the state. ${ }^{64}$

Of the states examined only two--Ohio and Michigan-limit by statute the number of state stores that may be established. In both instances a ratio based upon population is established. In Ohio the maximum is five to each county and one addi-

${ }^{01}$ See: for Va., Alc. Bev. Conr. Act. $\$ \$ 20-25$, supra note 57; W. VA. CoDE (1937) c. 60, art. IV; Oho Gen. Code (1938) \$6064 (14-28 incl.); Iowa Lie. Cont. Act \$\$29-32, supra note 9; Wash. State Liquor Acr $\$ \$ 23(A)-28$ incl., particularly $\$ 27$, Wash. Acts 1933; PA. Liquor Control Act (I933 as amended I935) $\$ 404,410$, PuRdon's Pa. Stat. tit. 47, \$744; and for Mich., Lie. Cont. Law $\$ \S 17-20$, supra note 47.

${ }^{02}$ Wash. State LiQ. Act $\$ 69$ (b) (general authority); Omo Gen. Code (I938) $\$ 6064$ (Ir).

${ }^{03}$ W. VA. CODE (1937) 60-3-15.

Be Wash. State Lie. Cont. BD., AnN. Reps (1934-I939) schedule c-3. 
tional for each thirty thousand population in excess of the first forty thousand.05 The Michigan statute authorized one store in each incorporated place of three thousand or more, and one for each forty thousand inhabitants of the county. The Ohio restriction includes agencies as well as stores but the Michigan standard apparently does not cover "specially designated distributors" that also sell for off-premise consumption. ${ }^{66}$

In addition to state operated stores several states designate private mercantile establishments as agencies of the state monopoly to supply areas where the operation of state stores may not be feasible. Ohio and West Virginia use the state agency as transitional devices-retail outlets to meet consumer demand until a state store can be located to serve the district. Particularly in West Virginia agents are subject to strict supervision with a view to maintaining as nearly as possible the same conditions of sale that are stipulated for state stores. ${ }^{67}$ The ratio of stores to agencies is surprisingly similar in the two states. Ohio operates 204 stores and 58 agencies; West Virginia, ro5 stores and 26 agencies. ${ }^{88}$

The Washington statute also authorizes the use of agencies but the ratio is reversed, 5I $^{\text {stores to }}$ I29 agencies. ${ }^{60}$ The Iowa commission, on the other hand, is authorized to establish agencies, but apparently has none in operation. ${ }^{70}$ In this connection it is worth noting that a proportionately large number of state stores, I70, is operated in the latter state. Michigan has a somewhat unique agency system. Any hotel or established merchant may be designated a "specially designated distributor."11 A distributor located more than one mile from a state store may sell from seven in the morning until two the succeeding morning. One situated within a mile of a store may sell only from seven until ten in the morning, and from six in the evening until two the following morning. The result is to make alcoholic liquors available for sale for off-premise consumption at any time except from two until seven in the morning. These conditions are more liberal than license sale for offpremise consumption in many of the license states. Agencies, moreover, are permitted to deliver orders placed personally by customers. ${ }^{72}$

Generally speaking there are no greater restrictions upon purchasers at state stores than are found in license states with respect to sales by licensees. Interdicted persons usually are minors, habitual drunkards, or intoxicated persons. In some states, West Virginia for example, customers fill out an order blank which includes a declaration that the purchaser is legally entitled to buy. This order, however, is more important for inventory control than for regulation. Two states-Washington and Iowa-re-

\footnotetext{
${ }^{05}$ Ohio Gen. Code (1938) $\$ 6064(\mathrm{II}) . \quad \quad{ }^{00}$ LIQ. Cont. Act $\$ 13$, supra note 47.

${ }^{67}$ See the interesting Rules and Regulations, and Manual of Specific Store and Agency Procedures, issued in 1939 by the West Virginia Liquor Control Commission.

${ }^{08}$ As of 1939 . See the annual reports of the state control agencies.

${ }^{69}$ Wash. State Lie. Act $\$ 69$, supra note 47.

${ }^{70}$ Jowa LiQ. Cont. Acr $\$ 10$, supra note 6r. $\quad{ }^{21}$ LiQ. Cont. Act $\$ x_{4}$, sutpra note 47.

${ }^{72}$ Mich. Liq. Cont. Comm., Rules and Regulations for Specially Designated Distributors, effective Nov. I, 1937 .
} 
quire the purchaser to obtain a personal permit to buy. In Washington this permit may be revoked if the holder becomes an interdicted person and the grounds are explicitly stated in the statute. ${ }^{73}$ In Iowa a personal permit is also required which may be revoked for non-support or desertion of dependents in addition to the usual grounds. ${ }^{74}$ The state commission, moreover, is authorized to prescribe the kind and quantity of liquor that may be purchased. In a most unusual and rather questionable exercise of this power the commission has prohibited persons on work relief, whether local, state or national, from purchasing. In addition the limitation of sales to permit holders, as to "kind, quantity and character" is left in the absolute discretion of the manager of the liquor store. ${ }^{75}$ So far as has been discovered this is the most stringent and uncontrollable restriction upon individual purchasers of legal liquor in the United States.

In brief, the monopoly method of liquor sale accomplishes its regulatory purposes by competition with illegal beverages and except in one instance, Iowa, attempts no direct restraint upon the individual purchaser not commonly found in the license states. The purpose of the monopoly is achieved if purchases are confined to legal channels which assure quality and fair price to the buyer and a reasonable profit from sale to the state. Control that can be clumsy and difficult when attempted through regulatory action is relatively simple when effected through the monopoly system. Manufacturers, importers or distributors who commit acts of dubious propriety can simply be excluded from doing business with the monopoly. Specifications of beverages and samples are required and deliveries are rigidly checked by chemical analysis to assure standards of potability and uniformity of quality. Transportation is by state trucks or under contract. Thus all other movements are presumptively illegal. Elaborate and systematic internal controls of inventory, stock movement and sales volume permit precise measurement of sales trends, stock requirements and customer demand. Most of this internal routine is geared to business machine operations. The atmosphere of the state store, moreover, is carefully arranged to avoid the stimulation of customer demand. No brands are recommended, no price wars occur, and there is never the problem of "loss leaders," inferior products or special sales.

Any estimate of the effectiveness of the monopoly system is beyond the scope of this treatment. Suffice it to point out that a very substantial amount of business is done by the monopoly states-in excess of $\$ 270,000,000$ in I939; generally speaking these beverages were marketed with a minimum of public scandal and complaint; and the monopoly method appears to have reduced the number of local areas going "bone-dry." Presumptively this is a good record-and a particularly laudable one when it is considered that the state store system was the first large scale venture in proprietary control by American states.

\footnotetext{
${ }^{73}$ Wash. StATE LiQ. Acr $\$ \$ 12-r 9$, supra note 47 . A fee of 50 cents is charged. It appears that some 334,000 permits were sold during 1939.

74 Iown LiQ. Cont. Acr $\$ \$ 13,20-28$, supra note 9 . A fee of $\$ \mathrm{I}$ is charged and 170,000 permits were issued in 1939 .

${ }^{75}$ Iowa Liq. Cont. Comm., Regulation of Nov. 20, I935.
} 


\section{ConcLuston}

The broad perspective of liquor control activities by the various states shows no dominating pattern. On the contrary the observer sees, on the surface, a mosaic of many different regulatory devices, administrative institutions and control procedures. This infinite variety has not come by accident nor yet by express design. It is rather the consequence of a myriad of influences and pressures, some clear and obvious but others subtle and intangible. A deep-rooted repugnance for the public drinking place has, for example, led in some states to the prohibition of all sales by the drink. Yet administrative forms and institutions, constructed to apply such restrictions, are generally more conditioned by local political mores than by a formal theory of administrative organization.

There is no easy, simple formula for the evaluation of state liquor control, for there is no magic in any particular method for effecting public policy. No objective test is available unless it is one that estimates the degree to which the community standards are effectively, and efficiently, expressed through administrative forms. This is at best a test of experience that can be applied only over a long period of time and with a sensitive appreciation of the environment in which control efforts are applied. In this sense state liquor control is still very much in the laboratory stage, but the laboratory is so large in expanse and houses so many simultaneous experiments that accurate observation and reliable inference are all but impossible.

Viewed with an eye to the future, however, state efforts at liquor control are indeed a proving ground for regulatory method. Unique devices such as state administrative review of local ordinances, administrative appeals from local regulatory action, proprietary monopolies and discretionary restraints upon individual purchasers, to name only a few, are full of significance not alone to the rational development of liquor control, but also to the maturing of all efforts at the public regulation of economic activity. There is no other field of public action in which regulatory activity is so comprehensive, so extreme, and yet so diversified. Within its bounds the states may indeed develop and refine regulatory techniques that will find significant application in other fields of public control. 